\title{
The impact of diabetes on multiple avoidable admissions: a cross-sectional study
}

Joana Seringa ${ }^{1 *}$, Ana Patrícia Marques ${ }^{2,3}$, Bruno Moita $^{1,4}$, Cátia Gaspar ${ }^{1}$, João Filipe Raposo ${ }^{5,6}$ and Rui Santana ${ }^{2,3}$

\begin{abstract}
Background: Multiple admissions for ambulatory care sensitive conditions (ACSC) are responsible for an important proportion of health care expenditures. Diabetes is one of the conditions consensually classified as an ACSC being considered a major public health concern. The aim of this study was to analyse the impact of diabetes on the occurrence of multiple admissions for ACSC.

Methods: We analysed inpatient data of all public Portuguese NHS hospitals from 2013 to 2015 on multiple admissions for ACSC among adults aged 18 or older. Multiple ACSC users were identified if they had two or more admissions for any ACSC during the period of analysis. Two logistic regression models were computed. A baseline model where a logistic regression was performed to assess the association between multiple admissions and the presence of diabetes, adjusting for age and sex. A full model to test if diabetes had no constant association with multiple admissions by any ACSC across age groups.
\end{abstract}

Results: Among 301,334 ACSC admissions, 144,209 (47.9\%) were classified as multiple admissions and from those, 59,436 had diabetes diagnosis, which corresponded to 23,692 patients. Patients with diabetes were 1.49 times $(p<0,001)$ more likely to be admitted multiple times for any ACSC than patients without diabetes. Younger adults with diabetes (18-39years old) were more likely to become multiple users.

Conclusion: Diabetes increases the risk of multiple admissions for ACSC, especially in younger adults. Diabetes presence is associated with a higher resource utilization, which highlights the need for the implementation of adequate management of chronic diseases policies.

Keywords: Multiple admissions for ACSC, Diabetes, Multimorbidity

\section{Key points}

- Increased costs and length of stay on multiple admissions for ACSC where diabetes diagnosis is present;

- Increased risk of multiple admissions for ACSC by the presence of diabetes, and especially at younger adults with diabetes;

- The need to improve the management of chronic diseases through a set of strategies, such as health promotion and health education.

\footnotetext{
* Correspondence: joanaseringa@gmail.com

${ }^{1}$ NOVA National School of Public Health, Universidade NOVA de Lisboa,

Lisbon, Portugal

Full list of author information is available at the end of the article
}

\begin{abstract}
Background
Ambulatory Care Sensitive Conditions (ACSC) are defined as a group of medical conditions for which adequate ambulatory care can, potentially, prevent the need for hospital admission or the worsening of complications [1-5]. Admissions for ACSC are associated with worse quality of ambulatory care and represent a significant burden on health care systems and a negative experience to patients [6-8].

Within this concept, the subgroup of multiple admissions for ACSC has been gaining a growing importance. Multiple admissions for ACSC are characterized by the frequent utilization of inpatient care for ACSC by the same patient within a period of time [9]. While readmission assessment is mainly focused on quality of inpatient
\end{abstract}


and transitional care [10], the appraisal of multiple admissions allows the assessment of ambulatory care quality before and after discharge $[9,11]$. The occurrence of ACSC admissions is worrying and may highlight the need for specific interventions in order to correct the underlying processes of care, but the recurrence over time of this admissions may indicate systemic problems addressing patients' health needs.

Among other reasons, the presence of multiple chronic conditions challenges ambulatory care and increases the likelihood of admission for ACSC [12,13] and is associated with higher costs and healthcare utilization.

Diabetes is one of the most prevalent chronic disease worldwide with a strong growth trend [14-16]. A large number of diabetes-related comorbidities, such as cardiovascular diseases, nephropathy and depression are documented in the literature $[17,18]$ as well as multimorbidity in patients with diabetes. In Portugal, diabetes is the sixth most frequent ACSC main cause of admission, representing $3.9 \%$ of the total ACSC admissions [19]. Although it is not the most frequent ACSC, as principal diagnosis, diabetes may contribute to aggravate other chronic diseases, such as Chronic Obstructive Pulmonary Disease (COPD) [20] and congestive heart failure [21].

Diabetes requires adequate management, as to avoid serious micro and macrovascular complications with a huge impact on the quality of life to the individuals and a significant burden on healthcare and global economic systems [22]. Diabetes is associated with an increase in healthcare costs related either to a rising number of admissions and consumption of other medical resources or to absenteeism and loss of productivity [15]. However, the impact of diabetes on the occurrence of multiple admissions for ACSC has been neglected in previous studies. The aim of this study was to investigate the impact of diabetes on the occurrence of multiple admissions for ACSC.

\section{Methods}

\section{Data sources and selection criteria}

Data on inpatient admissions in all public Portuguese National Health Service (NHS) hospitals from 2013 to $2015(n=3,041,447)$ was used. This database contains a summary of each inpatient admission, including demographic and clinical characteristics, such as age, sex, diagnosis and procedures coded according with International Classification of Diseases, Version 9 - Clinical Modifications (ICD-9-CM). A unique anonymized patient identifier allowed the linkage of all admissions for each patient in any of the public hospitals.

We excluded admissions from individuals aged younger 18 years old, admissions to specialized hospitals and admissions with incomplete records (error diagnosis-related group, missing gender and missing patient identifier). Pregnancy childbirth and puerperium admissions, radiotherapy procedures, haemodialysis diagnosis on patients with chronic renal failure and patients with more than thirty admissions were also excluded, accounting for a total of 1,071,603 excluded admissions. The final sample contained 1,969,844 admissions associated to $1,220,363$ distinct patients.

\section{Variables}

We defined multiple admissions for ACSC as the outcome measure of our study. An indicator variable assuming value 1 was created if, over the three years considered, the patient had more than one admission for any ACSC.

ACSC were identified by the Prevention Quality Indicators (PQIs) methodology defined by the Agency for Healthcare Research and Quality (AHRQ) [23]. PQIs methodology is based on a review and selection process that has made it a standard in this area of research [24]. This methodology also allows a detailed analysis of admissions for ACSC related to diabetes since four of the PQIs are directly related to this disease. We used the PQI 90 Overall composite that includes 11 validated PQIs for the adult population (Additional file 1: for PQI 90 details) [23].

A diabetes case was defined if any diagnosis within category 250 from ICD-9-CM was present. Risk associated to comorbidities was assessed using an enhanced version of Charlson Comorbidity Index (CCI) [25]. Costs per admission were estimated using the Diagnosis Related Groups (DRG) Portuguese NHS prices defined for the analysed years $[26,27]$.

\section{Statistical analysis}

We characterized multiple admissions for ACSC by sex, age group, type of admission, CCI, ACSC cause and estimated the average length of stay and the cost per admission comparing two distinct groups: admissions with and without diabetes. Chi-square test was used to compare proportions between groups. Mann-Whitney test was used to compare the average length of stay and estimated unit cost per admission in both groups.

Logistic regression was performed to assess the association between the chance of multiple admissions for any ACSC and the presence of diabetes adjusting for age and sex. In this baseline model (model 1), odds ratio estimates should be interpreted as the increased chance of multiple admissions for ACSC if a patient has diabetes, controlling for patients' age and sex.

To test for the hypothesis that the association between diabetes and the chance of multiple admissions by any ACSC is not constant across the age groups, an interaction term between diabetes and age was computed 
and modelled in the regression analysis. In this model (model 2), diabetes odds ratio should be interpreted as the increased chance of multiple admissions difference in patients at age reference category (18-39 years old). Simultaneously, age group odds ratio should be interpreted as the increased chance of multiple admissions to reference category age group if patients doesn't have diabetes (diabetes $=0$ ). To obtain the increased chance of multiple admissions for any ACSC in a specific age group between patients with and without diabetes, interaction coefficient should be multiplied by diabetes coefficient.

Given that AHRQs methodology for classification of ACSC admissions included 4 out of 11 PQIs directly related to diabetes, and assuming the hypothesis that our results could have been influenced and overestimated by the model itself, a sensitive analysis was performed to test the risk of multiple admissions by the presence of diabetes on admissions whose main diagnosis of admission was not diabetes. We chose to analyse bacterial pneumonia, heart failure and urinary tract infections (UTI) since these three conditions were the most frequent cause of admission in our sample.

Statistical analyses were performed using SPSS software version 24.0. A level of significance $<0.05$, for a 95\% confidence interval, was defined.

\section{Results}

In this 3 year period, ACSC represented $15.3 \%$ of all admissions occurred at all public Portuguese NHS hospitals, corresponding to a financial burden of 710.023.509 $€$. Approximately $48 \%$ of these admissions were considered multiple admissions for ACSC and, of those, 41\% had a diabetes diagnosis, which corresponded to 59,436 admissions and 23,692 patients. Figure 1 illustrates the distribution of the number of admissions and the number of patients, separating single admissions and multiple admissions and subdividing by the presence or absence of diabetes.

Multiple admissions were more frequent in women (50.7\%), in patients with 65 years old or older (86.3\%) and in patients with CCI score of 1,2 or $3(65.2 \%)$. These admissions were mainly unplanned (95.4\%). Bacterial pneumonia was responsible for $30.3 \%$ of multiple admissions followed by heart failure and UTI that represented 26.6 and $16.8 \%$ of multiple admissions, respectively. These results are summarized in Table 1, which also shows results comparing multiple admissions with and without diabetes diagnosis. A higher proportion of women was found in admissions where diabetes diagnosis was present either as principal or secondary cause of admission. Multiple admissions with diabetes diagnosis had a higher proportion of CCI with a score $2(24.1 \%)$ while in those without diabetes the score 1 was the most frequent (32.2\%). Moreover, in patients with diabetes, a score higher or equal to 7 was greater (5.4\%), when compared to patients without diabetes. Patients aged 80 years old or older represented $44 \%$ of cases and $93 \%$ of admissions were classified as unplanned admissions. Among diabetic multiple users, $65 \%$ of admissions were due to bacterial pneumonia, heart failure and UTI whereas diabetes as the principal cause of admission represented only $23 \%$ of admissions.

Table 2 summarizes the distribution of multiple admissions by cause of ACSC and by age categories. Causes of multiple admissions differ by age categories and by the presence of diabetes. Diabetic patients aged 18 to 39 years old causes of multiple admissions were driven by diabetes short and long-term complications that represented together $80.4 \%$ of admission in this age

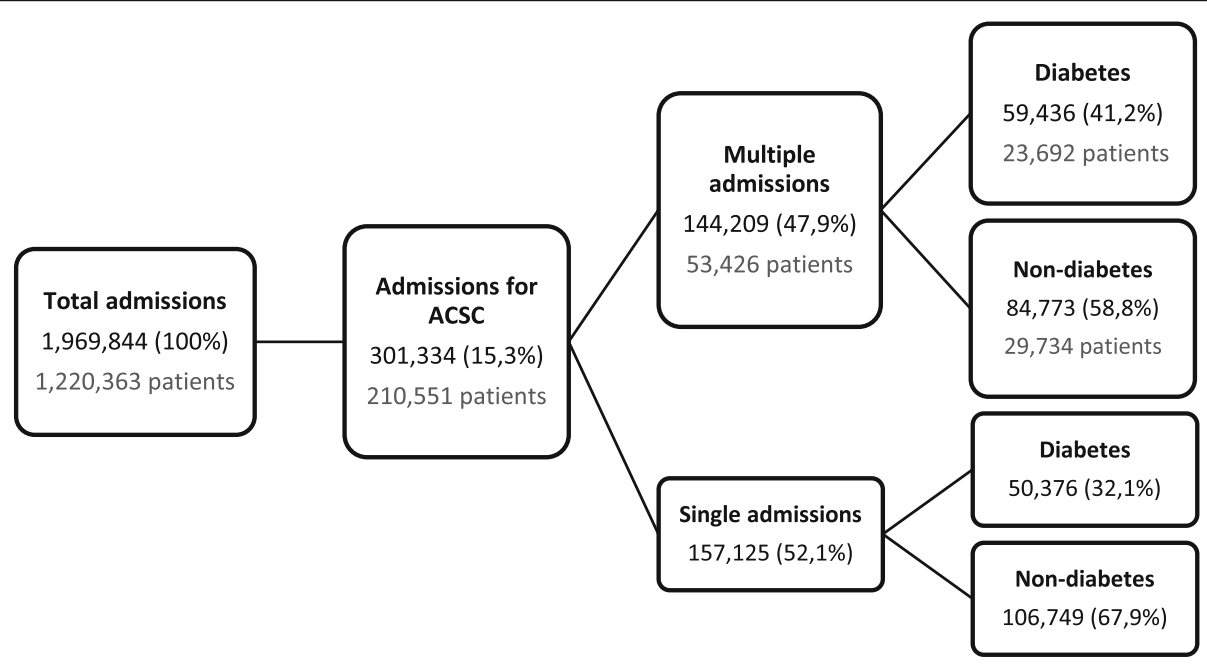

Fig. 1 Diagram of distribution of admissions, patients and total costs 
Table 1 Descriptive statistics: multiple admissions for ACSC with and without diabetes

\begin{tabular}{|c|c|c|c|c|c|c|}
\hline \multirow[b]{3}{*}{ Total Number } & \multicolumn{6}{|c|}{ Multiple Admissions for ACSC } \\
\hline & \multicolumn{2}{|c|}{ Diabetes N (\%) } & \multicolumn{2}{|c|}{ Without Diabetes N (\%) } & \multicolumn{2}{|c|}{ Total N (\%) } \\
\hline & 59,436 & $(41.2 \%)$ & 84,773 & $(58.8 \%)$ & 144,209 & $(100 \%)$ \\
\hline \multicolumn{7}{|l|}{ Sex } \\
\hline Female & 31,337 & $(52.7 \%)$ & 41,825 & $(49.3 \%)$ & 73,162 & $(50.7 \%)$ \\
\hline Male & 28,099 & $(47.3 \%)$ & 42,948 & $(50.7 \%)$ & 71,047 & $(49.3 \%)$ \\
\hline \multicolumn{7}{|l|}{ Age Group ${ }^{a}$} \\
\hline $18-39$ & 1187 & $(2.0 \%)$ & 1552 & $(1.8 \%)$ & 2739 & $(1.9 \%)$ \\
\hline $40-64$ & 8256 & $(13.9 \%)$ & 10,273 & $(12.1 \%)$ & 18,529 & $(12.8 \%)$ \\
\hline $65-79$ & 23,854 & $(40.1 \%)$ & 24,118 & $(28.5 \%)$ & 47,972 & (33.3\%) \\
\hline$\geq 80$ & 26,139 & (44.0\%) & 48,830 & (57.6\%) & 74,969 & $(53.0 \%)$ \\
\hline \multicolumn{7}{|l|}{ Admission Type ${ }^{a}$} \\
\hline Planned & 3794 & $(6.4 \%)$ & 2763 & $(3.3 \%)$ & 6557 & $(4.5 \%)$ \\
\hline Unplanned & 55,514 & $(93.4 \%)$ & 82,003 & $(96.7 \%)$ & 137,517 & $(95.4 \%)$ \\
\hline Others $^{b}$ & 128 & $(0.2 \%)$ & 7 & $(0 \%)$ & 135 & $(0.1 \%)$ \\
\hline \multicolumn{7}{|l|}{$\mathrm{CCl}^{\mathrm{a}}$} \\
\hline 0 & 0 & $(0.0 \%)$ & 11,431 & $(13.5 \%)$ & 11,431 & $(7.9 \%)$ \\
\hline 1 & 6413 & $(10.8 \%)$ & 27,273 & $(32.2 \%)$ & 33,686 & $(23.4 \%)$ \\
\hline 2 & 14,342 & (24.1\%) & 20,859 & (24.6\%) & 35,201 & $(24.4 \%)$ \\
\hline 3 & 12,476 & $(21.0 \%)$ & 12,673 & $(14.9 \%)$ & 25,149 & $(17.4 \%)$ \\
\hline 4 & 9869 & $(16.6 \%)$ & 7388 & $(8.7 \%)$ & 17,257 & (12.0\%) \\
\hline 5 & 8401 & $(14.1 \%)$ & 2541 & (3\%) & 10,942 & $(7.6 \%)$ \\
\hline 6 & 4698 & $(7.9 \%)$ & 1349 & $(1.6 \%)$ & 6047 & $(4.2 \%)$ \\
\hline$\geq 7$ & 3237 & $(5.4 \%)$ & 1259 & $(1.5 \%)$ & 4496 & $(3.1 \%)$ \\
\hline \multicolumn{7}{|l|}{ ACSC Cause ${ }^{a}$} \\
\hline Bacterial Pneumonia & 13,645 & (23.0\%) & 29,983 & (35.4\%) & 43,628 & (30.3\%) \\
\hline Heart Failure & 16,473 & $(27.7 \%)$ & 21,820 & $(25.7 \%)$ & 38,293 & $(26.6 \%)$ \\
\hline UTI & 9220 & $(15.5 \%)$ & 15,053 & (17.8\%) & 24,273 & $(16.8 \%)$ \\
\hline COPD or Asthma in Older Adults & 5140 & $(8.6 \%)$ & 14,195 & $(16.7 \%)$ & 19,335 & $(13.4 \%)$ \\
\hline Diabetes long-term complications & 8402 & $(14.1 \%)$ & 0 & $(0.0 \%)$ & 8402 & $(5.8 \%)$ \\
\hline Dehydration & 1262 & $(2.1 \%)$ & 2325 & $(2.7 \%)$ & 3587 & $(2.5 \%)$ \\
\hline Diabetes short-term complications & 2000 & $(3.4 \%)$ & 0 & $(0.0 \%)$ & 2000 & $(1.4 \%)$ \\
\hline Lower-Extremity Amputation among Patients with Diabetes & 2330 & $(3.9 \%)$ & 0 & $(0.0 \%)$ & 2330 & $(1.6 \%)$ \\
\hline Uncontrolled Diabetes & 1139 & $(1.9 \%)$ & 0 & $(0.0 \%)$ & 1139 & $(0.8 \%)$ \\
\hline Hypertension & 940 & $(1.6 \%)$ & 1157 & $(1.4 \%)$ & 2097 & $(1.5 \%)$ \\
\hline Asthma in Younger Adults & 3 & $(0.0 \%)$ & 240 & $(0.3 \%)$ & 243 & $(0.2 \%)$ \\
\hline
\end{tabular}

${ }^{a}$ Applied Chi-Square test. Difference between groups statistically significant $(p \leq 0.001)$

bIncludes: 1 episode of private medicine and 134 episodes of Integrated Management System of Subscribers for Surgery (SIGIC)

category. Non-diabetic patients aged 18 to 39 years main causes of admission were UTI (43.9\%) and bacterial pneumonia (27.9\%). Different distribution of causes of multiple admissions was also observed in patients aged 40 to 64 years old when comparing patients with and without diabetes. $66.6 \%$ patients without diabetes were admitted due to COPD (33.9\%) and bacterial pneumonia (26.7\%) whereas $63.7 \%$ patients with diabetes were admitted due to long term diabetes complications (32.1\%) heart failure (19.6\%) and bacterial pneumonia (12.0\%). In the age categories of 65 to 79 years old and 80 years old and above more than $50 \%$ of multiple admissions in both groups were concentrated in two main causes namely heart failure and bacterial pneumonia.

As shown in Table 3, admissions with diabetes had a higher average of length of stay $(11.1 \pm 12.4$ days $)$ and a 
Table 2 Distribution of multiple admissions by cause of ACSC and by age categories between episodes with and without diabetes

\begin{tabular}{|c|c|c|c|c|c|c|c|c|c|c|c|c|c|c|c|c|}
\hline \multirow[t]{3}{*}{ ACSC cause } & \multicolumn{4}{|c|}{$18-39$ years } & \multicolumn{4}{|c|}{ 40-64 years } & \multicolumn{4}{|c|}{$65-79$ years } & \multicolumn{4}{|c|}{80 or more years } \\
\hline & \multicolumn{2}{|c|}{ Diabetes } & \multicolumn{2}{|c|}{$\begin{array}{l}\text { Non- } \\
\text { Diabetes }\end{array}$} & \multicolumn{2}{|c|}{ Diabetes } & \multicolumn{2}{|c|}{$\begin{array}{l}\text { Non- } \\
\text { Diabetes }\end{array}$} & \multicolumn{2}{|c|}{ Diabetes } & \multicolumn{2}{|c|}{$\begin{array}{l}\text { Non- } \\
\text { Diabetes }\end{array}$} & \multicolumn{2}{|c|}{ Diabetes } & \multicolumn{2}{|c|}{ Non-Diabetes } \\
\hline & (\#) & $\%$ & (\#) & $\%$ & (\#) & $\%$ & (\#) & $\%$ & (\#) & $\%$ & (\#) & $\%$ & (\#) & $\%$ & (\#) & $\%$ \\
\hline Diabetes short-term complications & 566 & $47.4 \%$ & 0 & $0.0 \%$ & 529 & $6.2 \%$ & 0 & $0.0 \%$ & 439 & $1.8 \%$ & 0 & $0.0 \%$ & 466 & $1.8 \%$ & 0 & $0.0 \%$ \\
\hline Diabetes long-term complications & 394 & $33.0 \%$ & 0 & $0.0 \%$ & 2732 & $32.1 \%$ & 0 & $0.0 \%$ & 3459 & $14.2 \%$ & 0 & $0.0 \%$ & 1817 & $6.9 \%$ & 0 & $0.0 \%$ \\
\hline COPD or asthma in older adults & 0 & $0.0 \%$ & 0 & $0.0 \%$ & 767 & $9.0 \%$ & 3484 & $33.9 \%$ & 2428 & $10.0 \%$ & 5488 & $22.8 \%$ & 1945 & $7.3 \%$ & 5223 & $10.7 \%$ \\
\hline Hypertension & 3 & $0.3 \%$ & 39 & $2.5 \%$ & 121 & $1.4 \%$ & 172 & $1.7 \%$ & 384 & $1.6 \%$ & 305 & $1.3 \%$ & 432 & $1.6 \%$ & 641 & $1.3 \%$ \\
\hline Heart failure & 16 & $1.3 \%$ & 133 & $8.6 \%$ & 1673 & $19.6 \%$ & 1841 & $17.9 \%$ & 7342 & $30.2 \%$ & 6465 & $26.8 \%$ & 7442 & $28.1 \%$ & 13,381 & $27.4 \%$ \\
\hline Dehydration & 8 & $0.7 \%$ & 25 & $1.6 \%$ & 85 & $1.0 \%$ & 109 & $1.1 \%$ & 426 & $1.8 \%$ & 492 & $2.0 \%$ & 743 & $2.8 \%$ & 1699 & $3.5 \%$ \\
\hline Bacterial pneumonia & 44 & $3.7 \%$ & 433 & $27.9 \%$ & 1024 & $12.0 \%$ & 2739 & $26.7 \%$ & 4880 & $20.0 \%$ & 7650 & $31.7 \%$ & 7697 & $29.0 \%$ & 19,161 & $39.2 \%$ \\
\hline UTI & 79 & $6.6 \%$ & 682 & $43.9 \%$ & 827 & $9.7 \%$ & 1928 & $18.8 \%$ & 3581 & $14.7 \%$ & 3718 & $15.4 \%$ & 4733 & $17.9 \%$ & 8725 & $17.9 \%$ \\
\hline Uncontrolled diabetes & 70 & $5.9 \%$ & 0 & $0.0 \%$ & 243 & $2.9 \%$ & 0 & $0.0 \%$ & 382 & $1.6 \%$ & 0 & $0.0 \%$ & 444 & $1.7 \%$ & 0 & $0.0 \%$ \\
\hline Asthma in younger adults & 3 & $0.3 \%$ & 240 & $15.5 \%$ & 0 & $0.0 \%$ & 0 & $0.0 \%$ & 0 & $0.0 \%$ & 0 & $0.0 \%$ & 0 & $0.0 \%$ & 0 & $0.0 \%$ \\
\hline $\begin{array}{l}\text { Lower-extremity amputation } \\
\text { among patients with diabetes }\end{array}$ & 11 & $0.9 \%$ & 0 & $0.0 \%$ & 516 & $6.1 \%$ & 0 & $0.0 \%$ & 1019 & $4.2 \%$ & 0 & $0.0 \%$ & 784 & $3.0 \%$ & 0 & $0.0 \%$ \\
\hline
\end{tabular}

higher average unit cost of the admission (2543 $\pm 2797 €)$ when compared to admissions without diabetes (10.0 \pm 9.3 days) and $(2261 \pm 2135 €)$, respectively. These differences were found to be statistically significant accordingly with Mann-Whitney Test $(p<0.001)$.

Baseline model (model 1) results presented in Table 4 show that the presence of diabetes increases the chance of multiple admissions for any ACSC by 1.49 times, adjusting for age and sex. The chance of multiple admissions increases by 1.13 times for males and rises with age.

Assuming that diabetes effect varies over age, we have found that the presence of diabetes was associated with an increased risk of multiple use in younger ages relatively to older ages as shown in model 2 presented in Table 4. Patients aged 18-39 years old with diabetes are 4.08 times more likely to become multiple users than patients with the same age but without diabetes. Additionally, the increased chance of multiple admissions among diabetic patients was 1.79 times higher for patients aged
40-64 years old, 1.44 times for patients aged 65-80 years old and 1.37 times for patients aged 80 or older.

These results confirm the advanced hypothesis that the association between diabetes and the chance of multiple admissions by any ACSC is not constant across the age groups, once the interaction coefficients are significative.

The sensitive analysis, adjusted for gender and age group, allowed us to verify that, although the risk of multiple avoidable admission for diabetes slightly reduces when only three of the most prevalent avoidable conditions (bacterial pneumonia, heart failure and UTI) are analysed, the trend of increased risk of multiple avoidable admission by the presence of diabetes remains (Odds Ratio =1.40). The table with the analysis can be found on Additional file 2.

\section{Discussion}

In this study, we analysed the association between diabetes and multiple admissions for ACSC in Portugal.

Table 3 Comparison between multiple admissions for ACSC, with and without diabetes, regarding the length of stay and estimated unit cost per admission

\begin{tabular}{|c|c|c|c|}
\hline Multiple admissions for ACSC & & Diabetes & Non-diabetes \\
\hline \multirow[t]{4}{*}{ Average length of stay (days) $^{a}$} & Mean & 11.10 & 10.00 \\
\hline & Median & 8.0 & 8.0 \\
\hline & Standard deviation & 12.42 & 9.30 \\
\hline & Range & $0-700$ & $0-266$ \\
\hline \multirow[t]{4}{*}{ Estimated unit cost per admission $(€)^{a}$} & Mean & 2543 & 2261 \\
\hline & Median & 1938 & 1938 \\
\hline & Standard deviation & 2797 & 2135 \\
\hline & Range & 423-133,504 & 537-133,504 \\
\hline
\end{tabular}

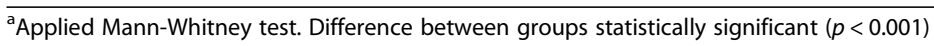


Table 4 Analysis of the association between diabetes and multiple admissions for ACSC over age $(n=301,334)$

\begin{tabular}{|c|c|c|}
\hline & (Model 1) & (Model 2) \\
\hline \multicolumn{3}{|l|}{ Gender } \\
\hline \multirow[t]{2}{*}{ Female } & $0.885^{* * *}$ & $0.889^{* * *}$ \\
\hline & $(0.0111)$ & $(0.0111)$ \\
\hline \multicolumn{3}{|l|}{ Age Group } \\
\hline \multirow[t]{2}{*}{$40-64$} & $1.661^{* * *}$ & $2.083^{* * *}$ \\
\hline & $(0.0404)$ & $(0.0493)$ \\
\hline \multirow[t]{2}{*}{$65-80$} & $2.387^{* * *}$ & $3.269^{* * *}$ \\
\hline & $(0.0388)$ & $(0.0471)$ \\
\hline \multirow[t]{2}{*}{$80+$} & $2.742^{* * *}$ & $3.785^{* * *}$ \\
\hline & $(0.0382)$ & $(0.0462)$ \\
\hline \multicolumn{3}{|c|}{ Interaction between age group and diabetes } \\
\hline \multirow[t]{2}{*}{ Diabetes diagnosis $(=1)$} & $1.492^{* * *}$ & $4.084^{* * *}$ \\
\hline & $(0.0110)$ & $(0.0817)$ \\
\hline \multirow[t]{2}{*}{ 40-64 \# diabetes diagnosis $(=1)$} & & $0.439^{* * *}$ \\
\hline & & $(0.0867)$ \\
\hline \multirow[t]{2}{*}{ 65-80 \# diabetes diagnosis $(=1)$} & & $0.352^{* * *}$ \\
\hline & & $(0.0837)$ \\
\hline \multirow[t]{2}{*}{$80+\#$ diabetes diagnosis $(=1)$} & & $0.336^{* * *}$ \\
\hline & & $(0.0831)$ \\
\hline \multirow[t]{2}{*}{ Constant } & $0.359^{* * *}$ & $0.266^{* * *}$ \\
\hline & $(0.0378)$ & $(0.0458)$ \\
\hline
\end{tabular}

Robust standard errors in parentheses

${ }^{*} p<0.05,{ }^{* *} p<0.01,{ }^{* * *} p<0.001$

From 2013 to 2015, ACSC were responsible for $15.3 \%$ of all admissions to all public Portuguese NHS hospitals inpatient services. Approximately $41 \%$ of multiple ACSC admissions had a diabetes diagnosis, corresponding to 59,436 admissions, associated to 23,692 patients. On average, the length of stay was longer on admissions with diabetes ( $11 \pm 12$ days), when comparing with nondiabetes (10 \pm 9 days), and medical expenditures were, on average, higher on admissions with diabetes (2543 \pm $2797 €)$, compared with non-diabetes (2261 $\pm 2135 €)$. Causes of multiple admissions differ by age categories and by the presence of diabetes. Patients with diabetes were 1.49 times $(p<0,001)$ more likely to be admitted multiple times for any ACSC than non-diabetic patients. The presence of diabetes was associated with an increased risk of multiple use in younger ages relatively to older ages.

Admissions with diabetes diagnosis had a higher length of stay and higher costs per admission. This finding is in agreement with the literature confirming that diabetes contributes to a longer hospital stay [28], which consequently increases the average cost per admission.

In our study, the most prevalent ACSC was bacterial pneumonia, heart failure and UTI even on admissions with a diabetes diagnosis, which is consistent with results found by Kim et al. [29]. Our analysis showed that the cause of admission varies across age groups and with the presence or absence of diabetes. At older ages, the most prevalent causes of admission, by diabetic patients, were no longer those that directly related to diabetes but other conditions such as bacterial pneumonia and heart failure. We hypothesize that this variation is due to a higher burden of multimorbidity at older age groups [30]. A more in-depth study of the interaction between diabetes and other specific ACSC is needed to better understand their relationship with the likelihood of potentially avoidable admissions across the various age groups.

Younger diabetic patients had a relative higher risk of being multiple users of ACSC than those at older age groups. An explanation for this finding might be related to a worse glycemic control in younger patients and a possibly higher proportion of type 1 diabetes in this group. Berkowitz, Meigs and Wexler found that, even though people younger than 65 years have fewer comorbid conditions, they also have inferior glycemic control [31]. This may be explained by the social characteristics of this age group. Younger adults may be more focused on developmental tasks, such as employment, than on the management of their disease [32]. Poor health habits, such as malnutrition (high intake of trans fats), decreasing physical activity, alcohol and smoking consumption and high levels of stress may be some of the factors that difficult the management of the disease [32]. Another possible explanation for this finding may be related to differences in the pathophysiology of diabetes between older and younger adults [33].

Our results may also be interpreted by a healthcare system organization point of view. The occurrence of potentially avoidable admissions, which had the potential to be prevented through outpatient care, warns for some system inefficiency, but the recurrence of these admissions possibly points out systemic problems in responding to the needs of individuals. Therefore our results may reinforce the potential for improvement in the management of chronic diseases, such as diabetes, through quality outpatient care. Health care management strategies, particularly in a context of increasing complexity, are needed due to the increased prevalence of individuals with multiple chronic diseases and comorbidities, but also due to the need to contain costs in the area of health care.

There are limitations to our study. First, admissions for ACSC identified in the present study are only suggestive of potentially avoidable admissions since some of the admissions were necessary and could not have been avoided even with optimal outpatient care, once the natural worsening of the health status of individuals with 
chronic diseases can motivate and justify admission [34], so we reckon the possibility of overestimating the number of potentially avoidable admissions. Additionally, we used only administrative data which provide a set of relevant representative and appropriate information of the study of this phenomenon but has a set of wellknown limitations related to the quality of the information, in particular regarding the codification of diagnosis [35]. Although we considered a set of control variables related to health status and demographic aspects, namely sex, age group and $\mathrm{CCI}$, we acknowledge that it could be interesting to analyse socioeconomic and provision of health services variables since some studies concluded that those variables have an association with ACSC admissions.

\section{Conclusions}

In conclusion, our results demonstrate a relevant association between diabetes, a chronic and complex disease, and the occurrence of multiple admissions for ACSC.

The findings highlight the need to define and prioritize a set of strategies, structured, both locally and organizationally, specially oriented to younger adults such as health promotion and health education, to improve the management of chronic diseases and reduce its consequences. Notwithstanding the contributions of the present study, we emphasize that future research is important, not only to better understand this phenomenon and its relation with other diseases, but also to define and implement effective strategies in order to reduce potentially avoidable admissions and their multiplicity.

\section{Supplementary information}

Supplementary information accompanies this paper at https://doi.org/10. 1186/s12913-019-4840-4

Additional file 1. Composite Prevention Quality Indicators (PQIs) - PQI 90 Overall composite.

Additional file 2: Table S4. Logistic regression sensitivity analysis of the 3 most prevalent and non-related diabetes avoidable conditions, adjusted odds ratios (AOR) by sex and age group.

\section{Abbreviations}

ACSC: Ambulatory care sensitive conditions; AHRQ: Agency for Healthcare Research and Quality; CCI: Charlson Comorbidity Index; COPD: Chronic Obstructive Pulmonary Disease; DRG: Diagnosis Related Groups; ICD-9CM: International Classification of Diseases, Version 9 - Clinical Modifications; NHS: National Health Service; PQIs: Prevention Quality Indicators; UTI: Urinary Tract Infections

\section{Acknowledgements}

The authors are grateful to all members of the NOVASaúde project for their suggestions and comments.

\section{Disclaimer}

Part of the work developed under this article was presented in an abstract submitted to the 11th European Public Health Conference in May 2018 and accepted in June 2018 for E-Poster walk.

\section{Authors' contributions}

All authors contributed substantially to the design and execution of this study and have approved the manuscript. JS and APM analysed and interpreted the data and drafted and revised the manuscript. BM performed the data preparation, contributed to the statistical analysis and to the data interpretation and critically reviewed the manuscript. CT, JFR e RS critically reviewed the manuscript. RS and JFR coordinated the investigation.

\section{Funding}

This investigation received financial support from NOVASaúde.

\section{Availability of data and materials}

The data that support the findings of this study are available from Administração Central do Sistema de Saúde (ACSS), I.P., but restrictions apply to the availability of these data, which were used under license for the current study, and so are not publicly available. Data are however available from the authors upon reasonable request and with permission of Administração Central do Sistema de Saúde (ACSS), I.P.

Ethics approval and consent to participate

Consent to participate is not applicable since anonymized patient-level data was used in the study.

The utilization of the data was approved both from Administração Central do Sistema de Saúde (ACSS), I.P. and the Escola Nacional de Saúde Pública, Universidade NOVA de Lisboa.

Consent for publication

Not applicable.

\section{Competing interests}

Prof. João Filipe Raposo, M.D., Ph.D., exercise coordinating, executive and management functions at Associação Protetora dos Diabéticos de Portugal.

\section{Author details}

${ }^{1}$ NOVA National School of Public Health, Universidade NOVA de Lisboa, Lisbon, Portugal. ${ }^{2}$ NOVA National School of Public Health, Public Health Research Centre, Universidade NOVA de Lisboa, Lisbon, Portugal. ${ }^{3}$ Comprehensive Health Research Center (CHRC), Lisbon, Portugal. ${ }^{4}$ Algarve University Hospital Center, Faro, Portugal. ${ }^{5}$ NOVA Medical School, Universidade NOVA de Lisboa, Lisbon, Portugal. ${ }^{6}$ Associação Protectora dos Diabéticos de Portugal, Lisbon, Portugal.

Received: 27 September 2019 Accepted: 16 December 2019

Published online: 27 December 2019

\section{References}

1. Agency for Healthcare Research and Quality. Guide to Prevention Quality Indicators: Hospital Admission for Ambulatory Care Sensitive Conditions. 2001.

2. Ansari Z, Carson N, Serraglio A, Barbetti T, Cicuttini F. The Victorian ambulatory care sensitive conditions study: reducing demand on hospital services in Victoria. Aust Health Rev. 2002.

3. Nedel FB, Facchini LA, Martín-Mateo M, Vieira LAS, Thumé E. Family Health Program and ambulatory care-sensitive conditions in Southern Brazil. Rev Saude Publica; 2008

4. Rosano A, Loha CA, Falvo R, Van Der Zee J, Ricciardi W, Guasticchi G, et al. The relationship between avoidable hospitalization and accessibility to primary care: a systematic review. Eur J Pub Health. 2013.

5. Kornelius E, Huang CN, Yang YS, Lu YL, Peng CH, Chiou JY. Diabetes-related avoidable hospitalizations in Taiwan. Prim Care Diabetes. 2014;8(4):330-7.

6. Vuik SI, Fontana G, Mayer E, Darzi A. Do hospitalisations for ambulatory care sensitive conditions reflect low access to primary care? BMJ Open: An observational cohort study of primary care usage prior to hospitalisation; 2017.

7. Weeks WB, Ventelou B, Paraponaris A. Rates of admission for ambulatory care sensitive conditions in France in 2009-2010: trends, geographic variation, costs, and an international comparison. Eur J Health Econ. 2016; 17(4):453-70.

8. Wannasri A, Nipaporn S, Inmai P, Sakunphanit T, Srithamrongsawat $\mathrm{S}$, Suriyawong paisal P. Development of ambulatory care sensitive conditions (ACSC) in Thai context: hospitalisation rates for ACSC as indicator of access 
and quality in primary care. BMC Public Health. 2014;14:O28. https:/doi.org/ 10.1186/1471-2458-14-S1-O28.

9. Matesanz-Fernández M, Monte-Secades R, Îniguez-Vázquez I, Rubal-Bran D, Guerrero-Sande H, Casariego-Vales E. Characteristics and temporal pattern of the readmissions of patients with multiple hospital admissions in the medical departments of a general hospital. Eur J Intern Med. 2015;26(10): 776-81

10. Fischer C, Lingsma HF, Marang-van De Mheen PJ, Kringos DS, Klazinga NS, Steyerberg EW. Is the readmission rate a valid quality indicator? A review of the evidence. PLoS One. 2014;9(11):e112282.

11. Etxeberria-Lekuona D, Casas Fernández de Tejerina JM, Méndez López I, Oteiza Olaso J, Arteaga Mazuelas M, Jarne Betran V. Multiple hospitalizations at the department of internal medicine of a tertiary hospital. Rev Clínica Española. English Ed. 2015;215:9-17. https://doi.org/10.1016/J.RCENG.2014. 08.001 .

12. Dantas I, Santana R, Sarmento J, Aguiar P. The impact of multiple chronic diseases on hospitalizations for ambulatory care sensitive conditions. BMC Health Serv Res. 2016;16(a):348.

13. Skinner HG, Coffey R, Jones J, Heslin KC, Moy E. The effects of multiple chronic conditions on hospitalization costs and utilization for ambulatory care sensitive conditions in the United States: a nationally representative cross-sectional study. BMC Health Serv Res. 2016:16-77.

14. International Diabetes Federation. IDF Diabetes Atlas. 7th ed. Brussels, Belgium: idf.org; 2015.

15. Seuring T, Archangelidi O, Suhrcke M. The economic costs of type 2 diabetes: a global systematic review. PharmacoEconomics. 2015;33(8):811-31.

16. Hu FB. Globalization of diabetes: the role of diet, lifestyle, and genes. Diabetes Care. 2011;34(6):1249-57.

17. Struijs JN, Baan CA, Schellevis FG, Westert GP, Van Den Bos GAM. Comorbidity in patients with diabetes mellitus: impact on medical health care utilization. BMC Health Serv Res. 2006;4:6-84.

18. Carper MM, Traeger L, Gonzalez JS, Wexler DJ, Psaros C, Safren SA. The differential associations of depression and diabetes distress with quality of life domains in type 2 diabetes. J Behav Med. 2014;37(3):501-10

19. World Health Organization. Ambulatory care sensitive conditions in Portugal. WHO Reg Off Eur. 2016

20. Gläser S, Krüger S, Merkel M, Bramlage P, Herth FJF. Chronic obstructive pulmonary disease and diabetes mellitus: a systematic review of the literature. Respir. 2015;89:253-64.

21. Mangini S, Vieira PP, Braga FGM, Bacal F. Detecting decompensated heart failure. Nurs Made Incred Easy! 2013;11:12-6.

22. Zhang P. Gregg E. The Lancet Diabetes and Endocrinology: Global economic burden of diabetes and its implications; 2017.

23. Agency for Healthcare Research and Quality. Quality Indicators Technical Specifications Updates. 2016.

24. Laditka JN, Laditka SB, Probst JC. Health care access in rural areas: evidence that hospitalization for ambulatory care-sensitive conditions in the United States may increase with the level of rurality. Heal Place. 2009;15(3):731-40

25. Quan H, Li B, Couris CM, Fushimi K, Graham P, Hider P, et al. Updating and validating the charlson comorbidity index and score for risk adjustment in hospital discharge abstracts using data from 6 countries. Am J Epidemiol. 2011.

26. Portaria n. 20/2014. Diário da República. Série I. 20. (2014-01-29): 597-703.

27. Portaria n. ${ }^{\circ}$ 234/2015. Diário da República. Série I. 153. (2015-08-07): 5516-5654.

28. American Diabetes Association. Economic costs of diabetes in the U.S. in 2012. Diabetes Care. 2013;36:1033-46.

29. Kim H, Helmer DA, Zhao Z, Boockvar K. Potentially preventable hospitalizations among older adults with diabetes. Am J Manag Care. 2011; 17(11):e419-26.

30. Puth MT, Weckbecker K, Schmid M, Münster E. Prevalence of multimorbidity in Germany: impact of age and educational level in a cross-sectional study on 19,294 adults. BMC Public Health. 2017:17(1):826.

31. Berkowitz SA, Meigs JB, Wexler DJ. Age at type 2 diabetes onset and glycaemic control: Results from the National Health and Nutrition Examination Survey (NHANES) 2005-2010. Diabetologia. 2013;56(12):2593600.

32. Jung SY, Lee SJ, Kim SH, Jung KM. A predictive model of health outcomes for young people with type 2 diabetes. Asian Nurs Res (Korean Soc Nurs Sci). 2015;9(1):73-80
33. Selvin E, Parrinello CM. Age-related differences in glycaemic control in diabetes. Diabetologia. 2013;56(12):2549-51.

34. Longman JM, Passey ME, Ewald DP, Rix E, Morgan GG. Admissions for chronic ambulatory care sensitive conditions-a useful measure of potentially preventable admission? BMC Health Serv Res. 2015;16:15-472.

35. De Coster C, Quan H, Finlayson A, Gao M, Halfon P, Humphries KH, et al, Identifying priorities in methodological research using ICD-9-CM and ICD-10 administrative data: report from an international consortium. BMC Health Serv Res. 2006:15:6-77.

\section{Publisher's Note}

Springer Nature remains neutral with regard to jurisdictional claims in published maps and institutional affiliations.
Ready to submit your research? Choose BMC and benefit from:

- fast, convenient online submission

- thorough peer review by experienced researchers in your field

- rapid publication on acceptance

- support for research data, including large and complex data types

- gold Open Access which fosters wider collaboration and increased citations

- maximum visibility for your research: over $100 \mathrm{M}$ website views per year

At $\mathrm{BMC}$, research is always in progress.

Learn more biomedcentral.com/submissions 